\title{
Cause-specific mortality: understanding uncertain tips of the disease iceberg
}

\author{
M J Goldacre
}

\begin{abstract}
Study objective-To determine the extent to which individual diseases, when recorded as being present shortly before death, were certified as causes of death.

Design-Retrospective cohort study in which the "subjects" were computerised linked records.

Setting-Six districts in the Oxford Regional Health Authority area (covering a population of 1.9 million people).

Subjects-Linked abstracts of hospital records and death certificates for people who died within four weeks and, for some diseases, within one year of hospital admission. Main outcome measures-The percentage of people with each disease for whom the disease was recorded as the underlying cause of death, was recorded elsewhere on the death certificate, or was not certified as a cause of death at all.
\end{abstract}

Results-Three broad patterns of certification are distinguished. Firstly, there were diseases that were usually recorded on death certificates when death occurred within four weeks of hospital care for them. Examples included lung cancer (on $91 \%$ of such death certificates), breast cancer $(92 \%)$, leukaemia and lymphoma $(90 \%)$, anterior horn cell disease $(89 \%)$, multiple sclerosis $(89 \%)$, myocardial infarction $(90 \%)$, stroke $(93 \%)$, aortic aneurysm (87\%), and spina bifida (89\%). These diseases were also usually certified as the underlying cause of death. Secondly, there were diseases which, when present within four weeks of death, were commonly recorded on death certificates but often not as the underlying cause of death. Examples included tuberculosis (on $76 \%$ of such certificates; underlying cause on $54 \%$ ), thyroid disease $(49 \% ; 21 \%)$, diabetes mellitus $(69 \% ; 30 \%)$ and hypertension $(43 \% ; 22 \%)$. Thirdly, there were conditions which, when death occurred within four weeks of their treatment, were recorded on the death certificate in a minority of cases only. Examples of these included fractured neck of femur (on $25 \%$ of such certificates), asthma (37\%), and anaemia (22\%). Not surprisingly, there was "convergence" in certification practice towards the common cardiovascular and respiratory causes of death. There was also evidence that conditions regarded as avoidable causes of death may not have been certified when present at death in some patients.

Conclusion-When uses are made of mortality statistics alone, it is important to know which category of certification practice the disease of interest is likely to be in. Linkage between morbidity and mortality records, and multiple cause analysis of mortality, would considerably improve the ability to quantify mortality associated with individual diseases.

f Epidemiol Community Health 1993; 47: 491-496

Mortality statistics are among the most universally used data on the occurrence of disease. They can be regarded as representing the extreme tip of the disease "iceberg", 1 but they represent an uncertain tip: the extent to which individual diseases are recorded on death certificates, when present in people who die, is unknown.

A disease may be present at death but not recorded on the death certificate for one of two main reasons. Firstly, its presence may be unknown to the doctor who certifies death. There are a number of published reports on the role of the necropsy to establish the cause of death in individual patients and, more generally, to advance clinical knowledge and the quality of death certification. ${ }^{2-17}$ The results of necropsy studies indicate that generalisations are difficult: for example, the contribution of necropsy findings to the accuracy of certification varies according to the disease, the patients' age, and, with increasing sophistication of non-invasive diagnostic methods in life, it probably also changes over time. Secondly, a disease which is present at death may be unrecorded because it is not considered to be sufficiently relevant to merit recording on the death certificate. To seek insights into the latter, record linkage was used to identify records of people who died soon after hospital inpatient care. Comparisons were made between the hospital record abstract and the death certificate to determine, by disease, the extent to which the main diagnosis on the former appeared as a cause of death on the latter.

\section{Method}

Data from the Oxford record linkage study (ORLS) were used. The ORLS includes computerised statistical abstracts of records of hospital admissions and death certificates organised so that successive records relating to the same person are linked together. ${ }^{18} 19$ Over the period covered by this paper, data collection was undertaken in all hospitals in six of the eight health districts of the Oxford region (population covered by data collection: 1.9 million). Death certificates were provided by the Office of Population Censuses and 
Surveys for all residents of the area covered, regardless of where death had occurred. All causes of death recorded on each certificate were coded by ORLS clerks according to the normal conventions of the International Classification of Diseases (ICD).$^{20}$ Computer linkage from hospital records to death certificates is known to be effected with a high degree of accuracy. ${ }^{21}$

Anonymised abstracts of records of inpatient care were used for all people admitted to hospital between 1979--86 with linkage to data from their death certificates to the end of 1987. Hospital records were analysed according to the main diagnosis on each record. Cohorts of records for each main diagnosis were constructed. When an individual had more than one hospital record for the same main diagnosis, the record selected for inclusion was the first in the period. When an individual had hospital records with different main diagnoses, each main diagnosis was included. The data were analysed to determine the extent to which each main diagnosis was recorded on the

Table I People who died within four weeks of hospital admission with each disease: percentage (and number) of people with the disease mentioned on the death certificate and with the disease as the underlying cause of death

\begin{tabular}{|c|c|c|c|}
\hline \multirow[b]{2}{*}{$\begin{array}{l}\text { Main diagnosis on } \\
\left.\text { hospital record (ICD code }{ }^{\star}\right)\end{array}$} & \multirow[b]{2}{*}{$\begin{array}{l}\text { All deaths } \\
\text { within } 4 \text { wks }\end{array}$} & \multicolumn{2}{|c|}{ Disease on death certificate } \\
\hline & & $\begin{array}{l}\text { Any mention } \\
(\%(\text { no) })\end{array}$ & $\begin{array}{l}\text { Underlying cause } \\
(\%(\text { no }))\end{array}$ \\
\hline Tuberculosis $(010-8,137)$ & 54 & $75.9(41)$ & $53 \cdot 7(29)$ \\
\hline Stomach cancer $(151)$ & 676 & $79 \cdot 9(540)$ & $72 \cdot 3(489)$ \\
\hline Lung cancer (162) & 2505 & $90 \cdot 9(2276)$ & $87 \cdot 9(2203)$ \\
\hline Breast cancer $(174)$ & 574 & $92 \cdot 2(529)$ & $84 \cdot 8(487)$ \\
\hline Cervical cancer $(180)$ & 73 & $79 \cdot 5(58)$ & $75 \cdot 3(55)$ \\
\hline Prostate cancer (185) & 344 & $85.5(294)$ & $69 \cdot 2(238)$ \\
\hline Leukaemia, lymphoma (200-8) & 675 & $89 \cdot 8(606)$ & $81 \cdot 3(549)$ \\
\hline Thyroid disease $(240-6)$ & 47 & $48.9(23)$ & $21 \cdot 3(10)$ \\
\hline Diabetes mellitus (250) & 373 & $68 \cdot 6(256)$ & $29 \cdot 8(111)$ \\
\hline Anaemia $(280-5)$ & 222 & $22 \cdot 1(49)$ & $10 \cdot 4(23)$ \\
\hline Parkinson's disease (332) & 106 & $61 \cdot 3(65)$ & $30 \cdot 2(32)$ \\
\hline Anterior horn cell disease ( 335 ) & 63 & $88 \cdot 9(56)$ & $81 \cdot 0(51)$ \\
\hline Multiple sclerosis $(340)$ & 26 & $88 \cdot 5(23)$ & $65.4(17)$ \\
\hline Hypertension $(401-5)$ & 172 & $43.0(74)$ & $22 \cdot 1(38)$ \\
\hline Ischaemic heart disease $(410-4,427-9)$ & 10635 & $90 \cdot 2(9596)$ & $77 \cdot 8(8271)$ \\
\hline Myocardial infarction (410) & 5.349 & $89.7(4797)$ & $85.6(4599)$ \\
\hline Stroke $(430-8)$ & 7396 & $92.5(6839)$ & $83.0(6138)$ \\
\hline Aortic aneurysm (441) & 600 & $86.5(519)$ & $80 \cdot 0(480)$ \\
\hline Pneumonia $(480-6)$ & 5731 & $86.5(4957)$ & $37 \cdot 8(2168)$ \\
\hline Asthma (493) & 92 & $40 \cdot 2(37)$ & $33.7(31)$ \\
\hline Peptic ulcer (531-4) & 628 & $68 \cdot 3(429)$ & $54 \cdot 3(341)$ \\
\hline Appendicitis (540-3) & 39 & $48 \cdot 7(19)$ & $30 \cdot 8(12)$ \\
\hline Hernia $(550-3)$ & 206 & $34.5(71)$ & $24 \cdot 3(50)$ \\
\hline Cirrhosis of liver $(571)$ & 176 & $77 \cdot 3(136)$ & $64 \cdot 2(113)$ \\
\hline $\begin{array}{l}\text { Nephritis, nephrosis, and nephrotic } \\
\text { syndrome }(580-9)\end{array}$ & & & \\
\hline syndrome $(580-9)$ & 1139 & $77 \cdot 3(880)$ & $32 \cdot 7(372)$ \\
\hline Spina bifida (741) & 27 & $88.9(24)$ & $81.5(22)$ \\
\hline Intracranial injury $(800-4,850-4)$ & 690 & $63.5(438)$ & $61 \cdot 3(423)$ \\
\hline Fractured neck of femur $(820)$ & 992 & $25 \cdot 4(252)$ & $16 \cdot 8(167)$ \\
\hline Other fracture of femur $(821)$ & 148 & $17 \cdot 6(26)$ & $13.5(20)$ \\
\hline $\begin{array}{l}\text { Poisoning by drugs and } \\
\text { medicaments }(960-79)\end{array}$ & 171 & $38.0(65)$ & $36 \cdot 8(63)$ \\
\hline Toxic effects of non-medicinal & 33 & $63 \cdot 6(21)$ & $63 \cdot 6(21)$ \\
\hline
\end{tabular}

${ }^{\star}$ Code or group of codes in the International Classification of Diseases (9th revision)

Table II People who died within one year of hospital admission with each disease: percentage (and number) of people with the disease mentioned on the death certificate and with the disease as the underlying cause of death

\begin{tabular}{|c|c|c|c|}
\hline \multirow[b]{2}{*}{$\begin{array}{l}\text { Main diagnosis on } \\
\text { hospital record (ICD code }\end{array}$} & \multirow[b]{2}{*}{$\begin{array}{l}\text { All deaths } \\
\text { within } 1 \text { year }\end{array}$} & \multicolumn{2}{|c|}{ Disease on death certificate } \\
\hline & & $\begin{array}{l}\text { Any mention } \\
(\%(n o))\end{array}$ & $\begin{array}{l}\text { Underlying cause } \\
(\%(\text { no }))\end{array}$ \\
\hline Stomach cancer $(151)$ & 1934 & $83.9(1622)$ & $79 \cdot 4(1535)$ \\
\hline Pancreatic cancer (157) & 1155 & $86 \cdot 0(993)$ & $81 \cdot 5(941)$ \\
\hline Lung cancer (162) & 6503 & $92 \cdot 9(6044)$ & $90 \cdot 5(5885)$ \\
\hline Breast cancer (174) & 1775 & $91.9(1632)$ & $85 \cdot 3(1514)$ \\
\hline Cervical cancer $(180)$ & 323 & $79 \cdot 3(256)$ & $75.9(245)$ \\
\hline Prostate cancer (185) & 1158 & $84 \cdot 3(976)$ & $69 \cdot 2(801)$ \\
\hline Leukaemia, lymphoma (200-8) & 2170 & $91 \cdot 2(1980)$ & $82 \cdot 8(1796)$ \\
\hline Diabetes mellitus (250) & 1355 & $64 \cdot 1(869)$ & $22 \cdot 6(306)$ \\
\hline Anterior horn cell disease ( 335 ) & 217 & $88.9(193)$ & $81 \cdot 1(176)$ \\
\hline Multiple sclerosis $(340)$ & 119 & $78 \cdot 2(93)$ & $51 \cdot 3(61)$ \\
\hline Cirrhosis of liver (571) & 400 & $71.8(287)$ & $56 \cdot 7(227)$ \\
\hline Spina bifida $(741)$ & 46 & $91 \cdot 3(42)$ & $78 \cdot 3(36)$ \\
\hline
\end{tabular}

patients' death certificates. In general, diagnoses were analysed at the three-digit level of the ICD. ${ }^{20}$ To allow for diagnostic cross-over between similar conditions with different codes at this level, however, some diagnostic codes were grouped (as indicated in table I). For example, the five ICD codes which cover hypertensive disease were grouped: patients who had one code for hypertension on the hospital record and a different three-digit code, but also for hypertension, on the death certificate were deemed to have the hospital diagnosis on the death certificate. Two main time periods were studied-deaths within four weeks and within one year of hospital admission. The former period was chosen on the assumption, discussed below, that a disease which required hospital admission within four weeks of death would usually have been relevant to, or at least present at, death. The latter period was chosen partly because similar reasoning applies to chronic diseases treated in the last year of life, and partly to determine, for such diseases, if certification was similar whether the four week or the full year period was used.

\section{Results}

A total of 55318 records were identified of people who died within four weeks of a hospital admission. As table I illustrates, there was wide variation between diseases in the extent to which the main hospital diagnosis was recorded on the death certificates. For example, it was on the death certificate for the great majority of people who died within four weeks of admission with a hospital diagnosis of lung cancer $(91 \%)$, breast cancer $(92 \%)$, leukaemia and lymphoma (90\%), anterior horn cell disease (which notably includes motor neurone disease, $89 \%$ ), multiple sclerosis (89\%), myocardial infarction $(90 \%)$, stroke $(93 \%)$, aortic aneurysm (87\%), and spina bifida ( $89 \%)$; and, for these diseases, it was usually recorded as the underlying cause of death. Other hospital diagnoses were commonly recorded on death certificates but were often not recorded as the underlying cause of death. Examples included diabetes mellitus (on $69 \%$ of death certificates after hospital admission with the disease, as the underlying cause on $30 \%$ ), thyroid disease, hypertension, Parkinson's disease and pneumonia (table I). Examples of diseases which were uncommonly recorded as the underlying cause of death within four weeks of hospital admission included fractured neck of femur (recorded as the underlying cause on $17 \%$ of death certificates of people who died within four weeks of admission for it), asthma, hernia, and anaemia.

For people with neoplastic or chronic disease, death certification within a year of hospital admission was generally similar to that within four weeks (table II). For example, the hospital diagnosis was recorded as the underlying cause of death within one year and within four weeks in $23 \%$ and $30 \%$ of people admitted to hospital with diabetes, $81 \%$ and $81 \%$ with anterior horn cell disease, $51 \%$ and $65 \%$ with multiple sclerosis, and $57 \%$ and $64 \%$ with cirrhosis of the liver. Most cancers were recorded slightly more commonly on death certificates in people who died within one year than within four weeks after hospital discharge. 
Hospital records linked to death certificates can be analysed to document certified causes of death in people admitted to hospital with any disease of interest. For example, of the 992 people who died within four weeks of admission with fractured neck of femur, the certified underlying causes of death included cancers, some of which had presumably caused pathological fractures, osteoporosis and, most commonly, circulatory and respiratory causes of death (table III). Of the 1355 people who died within a year of hospital admission for diabetes, the common certified underlying causes of death, when not diabetes, included cancers (141), heart disease (420), stroke (160), and pneumonia (111). Of 618 people with a hospital diagnosis of lung cancer in the year before death, but without lung cancer as the underlying

Table III Underlying causes of death on death certificates of patients who died within 4 weeks of hospital admission for fractured neck of femur

\begin{tabular}{|c|c|c|}
\hline $\begin{array}{l}\text { Underlying cause of } \\
\text { death (ICD code*) }\end{array}$ & No & $(\%)$ \\
\hline Neoplasms (140-208) & 43 & $(4 \cdot 3)$ \\
\hline Heart disease $(410-4,416-29)$ & 219 & $(22 \cdot 1)$ \\
\hline Stroke $(430-8)$ & 68 & $(6.9)$ \\
\hline Venous thrombosis and & & \\
\hline $\begin{array}{l}\text { embolism }(415,453) \\
\text { Pneumonia }(480-6)\end{array}$ & 47 & $(4 \cdot 7)$ \\
\hline Pneumonia $(480-6)$ & 171 & $(17 \cdot 2)$ \\
\hline Osteoporosis (733) & 45 & $(4 \cdot 5)$ \\
\hline Fractured neeck of femur (820) & 167 & $(16 \cdot 8)$ \\
\hline $\begin{array}{l}\text { Other and unspecified fracture } \\
\text { of femur }(821)\end{array}$ & 45 & $(4 \cdot 5)$ \\
\hline $\begin{array}{l}\text { Chronic obstructive airways } \\
\text { disease }(490-2,496)\end{array}$ & 48 & $(4 \cdot 8)$ \\
\hline Other & 139 & $(14 \cdot 0)$ \\
\hline Total & 992 & $(100 \cdot 0)$ \\
\hline
\end{tabular}

Table IV People who died within four weeks of hospital admission with each disease: selected chapters of the International Classification of Diseases showing percentage of people whose underlying cause of death was recorded in each chapter (numbers in parentheses)

\begin{tabular}{|c|c|c|c|c|}
\hline \multirow[b]{2}{*}{$\begin{array}{l}\text { ICD chapter of main } \\
\text { diagnosis on hospital record }\end{array}$} & \multicolumn{4}{|c|}{ Chapter of underlying cause of death (\% (no)) } \\
\hline & $\begin{array}{l}\text { Same as } \\
\text { hospital record }\end{array}$ & Circulatory & Respiratory & Other \\
\hline II Neoplasms $(n=11207)$ & $89 \cdot 6(10043)$ & $5 \cdot 2(581)$ & $3 \cdot 1(348)$ & $2 \cdot 1(235)$ \\
\hline $\begin{array}{l}\text { III Endocrine, nutritional and } \\
\text { metabolic diseases }(\mathrm{n}=642) \\
\text { VI Diseases of nervous system }\end{array}$ & $25 \cdot 5(164)$ & $36 \cdot 4(234)$ & $15 \cdot 1(97)$ & $22 \cdot 9(147)$ \\
\hline $\begin{array}{l}\text { and sense organs }(n=664) \\
\text { VII Diseases of circulatory }\end{array}$ & $37 \cdot 7(250)$ & $22 \cdot 1(147)$ & $13.9(92)$ & $26 \cdot 4(175)$ \\
\hline $\begin{array}{l}\text { system }(n=21394) \\
\text { VIII Diseases of respiratory }\end{array}$ & $85.9(18378)$ & - & $6 \cdot 4(1364)$ & $7 \cdot 7(1652)$ \\
\hline $\begin{array}{l}\text { system }(n=8456) \\
\text { IX Diseases of digestive system }\end{array}$ & $52 \cdot 1(4409)$ & $26 \cdot 7(2255)$ & - & $21 \cdot 2(1792)$ \\
\hline $\begin{array}{l}\quad(n=3206) \\
\text { XIV Congenital anomalies }\end{array}$ & $50 \cdot 1(1605)$ & $20 \cdot 9(669)$ & $10 \cdot 1(324)$ & $19 \cdot 0(608)$ \\
\hline $\begin{array}{l}(n=415) \\
X V I I \text { Injury and poisoning }\end{array}$ & $76 \cdot 9(319)$ & $6 \cdot 0(25)$ & $2 \cdot 4(10)$ & $14 \cdot 7(61)$ \\
\hline$(n=3074)$ & $40 \cdot 2(1236)$ & $29 \cdot 0(890)$ & $14 \cdot 9(457)$ & $16 \cdot 0(491)$ \\
\hline
\end{tabular}

Table $V$ People who died within four weeks of hospital admission with each disease, by age group (<65 years; 65-74 years; $75>$ years): percentage (and number) of people with the disease mentioned on the death certificate and with the disease as the underlying cause of death

\begin{tabular}{lllll}
\hline & & & \multicolumn{2}{l}{ Disease on death certificate (\% (no)) } \\
\cline { 3 - 5 } $\begin{array}{l}\text { Main diagnosis on } \\
\text { hospital record (ICD code) }\end{array}$ & $\begin{array}{l}\text { Age group } \\
(y)\end{array}$ & $\begin{array}{l}\text { All deaths } \\
\text { within } 4 \text { wks }\end{array}$ & $\begin{array}{l}\text { Any } \\
\text { mention }\end{array}$ & $\begin{array}{l}\text { Underlying } \\
\text { cause }\end{array}$ \\
\hline Lung cancer (162) & $<65$ & 634 & $93 \cdot 1(590)$ & $90 \cdot 9(576)$ \\
& $65-74$ & 964 & $90 \cdot 9(876)$ & $88 \cdot 1(849)$ \\
& $75>$ & 907 & $89 \cdot 3(810)$ & $85 \cdot 8(778)$ \\
Leukaemia (200-8) & $<65$ & 198 & $89 \cdot 9(178)$ & $82 \cdot 3(163)$ \\
& $65-74$ & 187 & $89 \cdot 3(167)$ & $82 \cdot 4(154)$ \\
Diabetes (250) & $75>$ & 290 & $90 \cdot 0(261)$ & $80 \cdot 0(232)$ \\
& $<65$ & 63 & $61 \cdot 9(39)$ & $31 \cdot 7(20)$ \\
Stroke (430-8) & $65-74$ & 117 & $71 \cdot 8(84)$ & $30 \cdot 8(36)$ \\
& $75>$ & 193 & $67 \cdot 9(131)$ & $27 \cdot 5(53)$ \\
& $<65$ & 1212 & $93 \cdot 7(1136)$ & $85 \cdot 6(1038)$ \\
Asthma (493) & $65-74$ & 1916 & $92 \cdot 3(1768)$ & $82 \cdot 3(1576)$ \\
& $75>$ & 4266 & $92 \cdot 2(3933)$ & $82 \cdot 6(3523)$ \\
& $<65$ & 32 & $46 \cdot 9(15)$ & $37 \cdot 5(12)$ \\
Fractured neck of femur (820) & $65-74$ & 29 & $41 \cdot 4(12)$ & $41 \cdot 4(12)$ \\
& $75>$ & 31 & $32 \cdot 3(10)$ & $22 \cdot 6(7)$ \\
& 665 & 24 & $16 \cdot 7(4)$ & $12 \cdot 5(3)$ \\
& $65-74$ & 85 & $20 \cdot 0(17)$ & $16 \cdot 5(14)$ \\
& $75>$ & 883 & $26 \cdot 2(231)$ & $17 \cdot 0(150)$ \\
\hline
\end{tabular}

cause of death, 311 were certified as deaths from other cancer sites and most of the remainder were deaths certified as cardiovascular or respiratory. Of the 312 people with a hospital diagnosis of stomach cancer in the year before death, but who did not have this diagnosis on the death certificate, the most common single underlying cause was cancer of the oesophagus ( 99 people). Of the 192 people with a hospital diagnosis of cancer of the oesophagus in the year before death, without the diagnosis on the death certificate, the most common single underlying cause of death was cancer of the stomach ( 88 people).

The data were also analysed to compare hospital diagnoses and causes of death within the broad groupings of the chapters of the ICD. This was done to provide summary measures of agreement and disagreement allowing for leeway in the accuracy of recording within each broad group of diseases. Illustrative results are shown in table IV. Of 11207 people who died within four weeks of admission for a neoplasm, $10043(90 \%)$ had an underlying cause of death in the chapter for neoplasms. Altogether 18378 of the 21394 people $(86 \%)$ who died within four weeks of an admission for circulatory diseases had a condition from within the circulatory chapter recorded as the underlying cause of death. About half the patients admitted with respiratory disease had an underlying cause of death in the respiratory chapter and about a quarter in the circulatory chapter. In general, when the underlying cause of death was not in the same chapter as the reason for the hospital admission, it was most commonly recorded as a circulatory death and next most commonly as a respiratory death.

Hospital diagnoses and causes of death on death certificates were compared within broad age groups in the expectation that agreement might be considerably less in the elderly than in others. In fact, whilst agreement was a little less common in the elderly, similarities in the pattern of certification between age groups were generally more striking than the differences. Illustrative examples are shown in table $\mathrm{V}$.

\section{Discussion}

STUDY DESIGN AND POSSIBLE ARTEFACTS OF METHOD

A disease which is coded on a hospital abstract may not be recorded on the death certificate for a number of reasons. Firstly, patients may die soon after hospital care from causes that are wholly unrelated to the reason for the admission. Whilst this doubtless occurred, in most individuals it seems unlikely that death shortly after hospital admission would be unrelated to the diseases present at admission. Secondly, the coded diagnosis on either record could sometimes be the result of a transcription or coding error. At the time covered by this study the staff responsible for collecting and coding data in the hospitals in the six districts for the ORLS were centrally trained, funded, supervised, and monitored by the ORLS. Checks on coding were made regularly and a number of studies have reported on the general reliability of the data. ${ }^{22-24}$ The high level of agreement found between hospital and death 
records for conditions where a high level of agreement might be anticipated (eg lung cancer, breast cancer, leukaemia, spina bifida) also suggests that there are no major intrinsic technical flaws in the record systems. Whilst some errors are possible, these are unlikely to be a major explanation for the general pattern of findings in this study.

The patients whose data are shown in table I are a selected subset of all patients with each disease because they were those who were admitted to hospital soon before death. It is difficult to judge how far the results might apply to a wider population of patients with each disease, including those who die without recent hospital care, and to national mortality statistics. There are, however, consistencies between the findings in this and other studies of different design. For example, when a cancer is present (or believed to be present) before death it is usually a certified cause of death although there may be variation between the ante mortem and necropsy diagnoses in respect of site. ${ }^{411}$ A study of 2134 members of the British Diabetic Association who died showed that diabetes was the underlying cause of death for $18 \%$ and was mentioned on the death certificates for $67 \%$ of the individuals. ${ }^{25}$ These figures compare with $23 \%$ and $64 \%$, respectively, in diabetics in the present study (table II). Studies in other countries have shown similar results for diabetes. ${ }^{26-29}$ Similar findings to those reported here have also been found elsewhere for fractured neck of femur, motor neurone disease, and cirrhotic liver disease. ${ }^{30-33}$

\section{EVIDENCE AND JUDGEMENT IN CERTIFYING DEATH}

Diagnostic information which was not available at the time of the hospital admission may have become evident closer to the time of the patient's death, or at necropsy, to alter the diagnosis which was made at the time of hospital care. This is the likely reason why, in people who died after an admission with a diagnosis of stomach cancer, the next most common certified cause of death after stomach cancer was oesophageal cancer. Conversely, in people who died after admission with a diagnosis of oesophageal cancer, the next most common certified cause of death after oesophageal cancer was stomach cancer. Routine linkage between hospital records and death certificates could be used to highlight clinical areas of diagnostic difficulty.

For some conditions it is possible that the levels of agreement shown here between the hospital and death records are spuriously high. If a patient has presented clinically shortly before death, the diseases which are known or believed to have been present at that time may be considered to be the causes of death by the certifying doctor who may therefore feel that a necropsy is not warranted. Emery pointed out that even where there is a necropsy, consistency of agreement between the clinician and pathologist is only a partial test of accuracy because the pathologist is aware of the patient's clinical history: "it is biased in favour of a persistent diagnosis". ${ }^{34}$ It is also possible that when a patient who has not been investigated shortly before death, dies, the last known major disease may be regarded as the cause of death.
This may account for the finding, which was not anticipated, that there tended to be closer agreement between the hospital diagnosis and the underlying cause of death in people who died from cancer at the longer time interval (table II) than the shorter time interval (table I) after hospital care.

The precise cause of death in patients with multiple pathologies may, of course, be a matter of almost arbitrary choice. For example, Pemberton commented that a doctor may judge that a patient who died after a fractured neck of femur would not have sustained the fracture and died if it had not been for underlying osteoporosis ${ }^{30}$; and that, in a particular patient, the fracture and death would not have occurred without underlying cerebrovascular pathology. ${ }^{31}$ Guralnick cited the example of choice between coronary heart disease and diabetes mellitus as the underlying cause of death in people who die with both. ${ }^{35}$ Underestimation of the contribution of individual diseases to mortality is an inevitable consequence of single-cause analysis of mortality statistics when multiple pathology is present. Much has been written about multiple-cause analysis ${ }^{34}{ }^{38}$ but it is uncommon. It would enable account to be taken more accurately of multiple pathologies in assessing the contribution of individual diseases to mortality; and it would aid assessment of variation in certification practice, and changes to certification rules over time, ${ }^{39} 40$ when underlying causes of death are chosen from several causes on the death certificate. Multiple cause coding has not been undertaken routinely, except in occasional years, for national mortality data in England. It is scheduled for introduction in the mid-1990s. It has been undertaken routinely in the ORLS and is used in the results in tables I and II ("underlying cause" and "any mention"). As the tables show, some of the "under-certification" of individual diseases seen when judged from "underlying cause" alone is substantially reduced when all certified causes are considered.

\section{IMPLICATIONS}

When a condition is known to be present at or shortly before death the certifying doctor may judge that it is not a contributing cause or that, if it is, it is not the underlying cause of death. In this study it is not possible to know the extent to which each recorded ante mortem disease actually contributed to death, but general conclusions can be drawn. Firstly, there were conditions which, when present or believed to be present at death, were usually entered on death certificates as the underlying cause of death; others which, when present, were commonly recorded on death certificates but often not as the underlying cause of death; and others which, when present at hospital admission shortly before death, were uncommonly recorded anywhere on death certificates. When uses are made of mortality statistics alone, it is important to know which category the disease of interest is likely to be in. Without such knowledge, causespecific mortality cannot be assumed to be a reliable measure of deaths associated with a given disease.

Just as population-based mortality rates for some diseases underestimate deaths associated 
with the condition, so they probably overestimate others. It is clear that there is "convergence" in certification towards common causes of death and in particular, convergence to cardiovascular and respiratory causes (eg tables III and IV). In some circumstances this may appropriately reflect a "final common pathway" from diverse pathology to death. In other circumstances it may reflect an insufficient distinction made in certification between the mode of dying and the cause of death. ${ }^{41}{ }^{44}$ It may also result from misunderstanding by clinicians of the process and rules of certification. ${ }^{12} 13+147$ Locally produced statistics like those in tables I-III, derived from linkage between hospital records and death certificates, could be used to raise questions about possible "under-certification" or "over-certification" of particular causes of death and thereby to help improve the quality of certification.

Some conditions are probably under-recorded on death certificates because the certifying doctor wishes to spare relatives the necessity of a necropsy and inquest ${ }^{30}$ or to avoid the distress of recording a stigmatising diagnosis. ${ }^{33}$ It also seems likely that conditions which are regarded as avoidable causes of death are often unrecorded. For example, conditions which have been used in statistical studies of "avoidable causes" of death in recent years ${ }^{4849}$ include hypertensive disease, tuberculosis, asthma, hernia, and anaemia which, when present shortly before death in the present study, were often not recorded as underlying causes of death (table I). Current "avoidable causes" also include pneumonia and bronchitis which were commonly recorded as underlying causes of death when other diseases were present: in part, the certification of these causes of death can probably be regarded as "convergence" to respiratory modes of dying rather than as sole causes of death. It follows that studies of avoidable causes of death, based on mortality statistics alone, should be interpreted with considerable caution. $^{50}$

Linkage of morbidity to mortality records is increasingly feasible with the increased availablity of morbidity data - in general practice as well as in the hospital setting - and with modern computer technology. It would enable insights to be gained, as a routine, into the extent to which diseases known to exist shortly before death are recorded on death certificates. It would facilitate the calculation of mortality associated with each disease in which the denominator consists of all people with the disease of interest and the numerator consists of all people from the denominator population who die within specified periods of time. These rates could be compared with the mortality experience of the general population. ${ }^{24}$ Record based "follow back" studies ${ }^{29} 51$ could also be routinely undertaken to identify conditions which preceded death from the certified causes of interest: for example, to study the extent to which deaths from myocardial infarction represent the certified terminal event in people with other major antecedent disease. In these ways the public health importance of mortality associated with individual diseases could be identified and interpreted more accurately than at present.

The Unit of Health-Care Epidemiology is funded by the Department of Health and the Oxford Regional Health
Authority. This study was funded by the Department of Health (grant number 121/2585). I thank Mrs Myfanwy Griffith for computer programming and Miss Liza Brandon and Ms Pam Evans for typing the manuscript.

1 Last JM. The Iceberg "Completing the clinical picture" in general practice. Lancet 1963; ii: $28-31$.

Cabot RC. Diagnostic pitfalls identified during a study of three thousand autopsies. $\mathscr{f} A M A$ A 1912; 59: $2295-8$.

3 Swartout HO. Antemortem and postmortem diagnoses. $N$ Engl f Med 1934; 211: 539-42.

Engl 7 Med $1934 ; 211$ : $539-42$.
Swartout HO, Webster RG. To what degree are mortality Swartout HO, Webster RG. To what degree are mortality
statistics dependable? Am f Public Health 1940; 30: 811-5. statistics dependable? Am f Public Health 1940; 30: 811-5.
Pohlen K, Emmerson H. Errors in clinical statements of Pohlen K, Emmerson H. Errors in clinical statements
causes of death. Am f Public Health 1943; 33: 505-16.

causes of death. Am $\mathcal{F}$ Public Health 1943; 33: $505-16$.
James G, Patton RE, Heslin AS. Accuracy of cause-ofJames G, Patton RE, Heslin AS. Accuracy of cause-of-
death statements on death certificates. Public Health Rep death statements
$1955 ; 70: 39-51$.

7 1955; 70: 39-51. Inquiry into diagnostic evidence supporting medical certifications of death. Am 7 Public Health 1958; 48 1376-87.

8 Heasman MA. Accuracy of death certification. Proc $R$ Soc Med 1962; 55: 733-6.

9 Heasman MA, Lipworth L. Accuracy of certification of cause of death. A report on a survey conducted in 1959 in 75 hospitals of the National Health Service to obtain information on the extent of agreement between clinical and post-mortem diagnoses. General Register Office. Studies on medical and population subjects, no 20. London: HMSO, 1966.

10 Cameron HM, McGoogan E. A prospective study of 1152 hospital autopsies; 1 . Inaccuracies in death certification. $\mathcal{f}$ Pathol 1981; 133: 273-83.

11 Cameron HM, McGoogan E. A prospective study of 1152 hospital autopsies; 2. Analysis of inaccuracies in clinical diagnoses and their significance. F Pathol 1981; 133: 285-300.

12 A joint report of the Royal College of Physicians and the Roval College of Pathologists. FR Coll Physicians Lond 1982 16: 206-18.

13 Alderson MR, Bayliss RIS, Clarke CA, Whitfield AGW. Death certification. BMF 1983; 287: 444-5.

14 Kircher T, Nelson J, Burdo H. The autopsy as a measure of accuracy of the death certificate. $N$ Engl $\mathscr{f}$ Med 1985; 313: accuracy

15 Karwinski B, Hartveit F. Death certification: increased clinical confidence in diagnosis and lack of interest in confirmation by necropsy is not justified. $\mathcal{F}$ Clin Pathol 1989; 42: $13-7$.

16 Riboli E, Delendie M. Autopsy in epidemiology and medical research. IARC Scientific Publications no 112. Lyon International Agency for Research on Cancer, 1991.

17 Royal College of Pathologists, Royal College of Physicians of London, and Royal College of Surgeons of England. The autopsy' and audit. London: Royal College of Pathologists, 1991.

18 Acheson ED. Medical record linkage. Oxford: Oxford University Press, 1967

9 Gill LE, Baldwin JA. Methods and technology of record linkage: some practical considerations. In: Baldwin JA Acheson ED, Graham WJ eds Textbook of medical record linkage. Oxford: Oxford University Press, 1987: 39-54

20 World Health Organisation. International classification of diseases. Mamual of the international statistical classification of diseases, injuries, and causes of death. London: HMSO, 1977.

21 Henderson J, Goldacre MJ, Griffith M, Simmons H Recording of deaths in hospital information systems: implications for audit and outcome studies. $\mathcal{F}$ Epidemiol Community Health 1992; 46: 297-9.

22 Goldacre MJ, Ingram RM. Changing workload in ophthalmology: some observations from routine statistics. BMff 1983; 286: $1560-61$

23 Sellar C, Goldacre MJ, Hawton K. Reliability of routine hospital data on poisoning as measures of deliberate selfhospital data on poisoning as measures of deliberate self-

24 Seagroatt V, Tan HS, Goldacre MJH, Bulstrode C, Nugent I, Gill L. Elective total hip replacement: incidence, I, Gill L. Elective total hip replacement: incidence,
emergency readmission rate, and postoperative mortality. emergency readmission rate,

25 Fuller JH, Elford J, Goldblatt P, Adelstein AM. Diabetes mortality: new light on an underestimated public health problem. Diabetologia 1983; 24: 336-41.

26 Waugh NR, Dallas JH, Jung RT, Newton RW. Mortality in a cohort of diabetic patients. Causes and relative risks. Diabetologia 1989; 32: 103-4.

27 Balkau B, Papoz L. Certification of cause of death in French diabetic patients. I Epidemiol Community Health 1992; 46 $63-5$.

28 Jougla E, Papoz L, Balkau B, Maguin P, Hatton F, Eurodiab Subarea $C$ Study Group. Death certificate coding practices related to diabetes in European countries - the "Eurodiab Subarea C" Study. Int F Epidemiology 1992; 21: 343-51.

29 Bild DE, Stevenson JM. Frequency of recording of diabetes on US death certificates: analysis of the 1986 nationa mortality followback survey. F Clin Epidemiol 1992; 45: 275-81.

30 Pemberton J, Cust G. An epidemic of osteoporosis? Community Medicine 1986; 8: 322-8.

31 Pemberton J. Are hip fractures under estimated as a cause of death? The influence of coroners and pathologists on the death? The influence of coroners and pathologists
death rate. Community Medicine 1988; 10: 117-23.

32 Buckley J, Warlow C, Smith P, Hilton-Jones D, Irvine S, Tew JR. Motor neuron disease in England and Wales, 1959-79. F Neurol Neurosurg Psychiatry 1983; 46: 197-205. 
33 Maxwell JD, Knapman P. Effect of coroners' rules on death certification for alcoholic liver disease. $B M 7$ 1985; 291: 708 .

34 Emery JL. Certification of death by the pathologist. Proceedings of the Royal Society of Medicine 1962; 55: 738-40.

35 Guralnick L. Some problems in the use of multiple causes of death Fournal of Chronic Diseases 1966; 19: 979-90.

36 Dorn HF. Some considerations in the revision of the international statistical classification. Public Health Rep 1964; 79: 175-9.

37 Dorn HF. Underlying and contributory causes of death. In: Haenszel W ed. Epidemiological approaches to the study of cancer and other chronic diseases. National Cancer Institute Monograph 19. Bethesda, Maryland: US Department of

8 Krueger DE. New numerators for old denominatorsmultiple causes of death. In: Haenszel W ed. Epidemiological approaches to the study of cancer and other chronic diseases. Ibid 431-43.

39 Erhardt CL, Weiner L. Changes in mortality statistics through the use of the New International Statistical Classification. Am f Public Health 1950; 40: 6-16.

40 Harvey I. Falls in death from respiratory disease (letter). Lancet 1991; 338 (877-9): 1407.

41 Leadbeatter S. Semantics of death certification. $f R$ Coll Physicians Lond 1986; 20: 129-32.

42 Knight B. The cause of death fR Soc Med 1986; 79: 191-2.

43 Zumwalt RE, Ritter MR. Incorrect death certification: an invitation to obfuscation. Postgrad Med 1987; 81: 245-54
44 Ashley JSA. Completion of medical certificates of cause of death. London: Office of Population Censuses and Surveys. Letter distributed to all general practitioners and hospital consultants in England, May 1990.

45 Niven R. The cause of death. F $R$ Soc Med 1986; 79: 623 .

46 Kircher T, Anderson RE. Cause of death: proper completion of the death certificate. $7 A M A 1987 ; 258: 349-52$.

47 Balaraian $\mathrm{R}$. Certification of death and the clinician. Health Trends 1983; 15: 53-6.

48 Charlton JRH, Hartley RM, Silver R, Holland WW. Geographical variation in mortality from conditions amenable to medical intervention in England and Wales. Lancet 1983; i: 691-6.

49 Mackenbach JP, Bouvier-Colle MH, Jougla E. "Avoidable" mortality and health services: a review of aggregate data mortality and health services: a review of aggregate data

50 Walsworth-Bell JP, Allen D. Deaths from conditions amenable to medical intervention: are they really avoidable? Lancet 1988; i: 1228 .

51 Moriyama IM, Dawber TR, Kannel WB. Evaluation of diagnostic information supporting medical certification of deaths in cardiovascular disease. In: Haenszel W ed. Epidemiological approaches to the study of cancer and other chronic diseases. National Cancer Institute Monograph 19. Bethesda, Maryland: US Department of Health, Education and Welfare, 1966; 405-19. 